\title{
HACIA UNA REDEFINICIÓN DE LAS HISTORIOGRAFÍAS LITERARIAS NACIONALES AFRICANAS: LOS EJEMPLOS DE SUDÁFRICA Y GUINEA ECUATORIAL
}

\author{
Lic. D. Juan Miguel Zarandona Fernández \\ Universidad de Valladolid. España
}

RESUMEN: Una historia de la literatura nacional de una nación africana como es el caso de Guinea Ecuatorial debe seguir una serie de criterios muy amplios que respete la complejidad histórica y cultural de la misma. El ejemplo de la nueva Sudáfrica y la creación de una nueva conciencia literaria nacional 'unida en su diversidad' puede ser muy útil para el caso de Guinea Ecuatorial.

PALABRAS CLAVE: Guinea Ecuatorial, Sudáfrica, literatura africana, historiografia, canon

ABSTRACT:A history of the national literature of a country such as Equatorial Guinea must follow a series of very ample criteria that respect its historical and cultural complexity. The example of the New South Africa and its creation of a new national literary conscience 'united in its diversity' can be very useful for the case of Equatorial Guinea.

KEY WORDS: Equatorial Guinea, South Africa, African literature, historiography, canon

\section{INTRODUCCIÓN}

La historiografia o la confección de historias de la literatura vuelve a estar de moda dentro del panorama de los estudios literarios de nuestro tiempo, como un complemento imprescindible de la teoria y de la crítica literarias. Después de decenios de abandono por parte de formalistas, estructuralistas y posestructuralistas, con conceptos como el close reading del New Criticism, es decir, el comentario estricto de los elementos del texto, sin tener en cuenta ni la época ni al autor, o la inquietante muerte del autor de Roland Barthes.

La nueva historiografia, por supuesto, debe estar pendiente de las nuevas aportaciones de nuestro siglo tanto de la critica y la teoria literaria. Y debe ser diacrónica, atenta a la historia y a la biografia -la documentación extrínsica-, y sincrónica, atenta a los textos de un 
momento dado, al mismo tiempo. La historiografia literaria, además, se mezcla hoy en día con el asunto debatidísimo e incluso violento, como ocurre en el caso de los Estados Unidos, del canon literario: con la constitución de éste, según opiniones, atendiendo a criterios estéticos, ideológicos o una combinación de ambos. Abierto o cerrado, igualmente, a todo tipo de minorías: raciales, sociales o culturales (Véase: Bloom 1996; Pozuelo 2000). Deberemos tener en cuenta estos datos a lo largo de nuestro trabajo.

\section{LAS LITERATURAS DE SUDÁFRICA Y GUINEA ECUATORIAL}

Guinea Ecuatorial, ese pequeño país de habla hispana, cuyos límites geográficos son fruto del fracaso de un tratado internacional para España, el de París de 1900, que redujo a una décima parte sus pretensiones coloniales en el territorio, permite sin embargo que la rica, peculiar y compleja realidad de África se exprese también, literariamente, en español. O lo que es lo mismo, que la experiencia, la voz de África también se deje oír en dicha lengua, y no sólo en las lenguas europeas de más fuerte implantación en el continente: inglés, francés y portugués, el grupo restringidisimo que se ha enriquecido con el magnifico caudal de la cultura africana. Los editores españoles, aunque tarde, parecen haberse dado cuenta, aunque todavía no muy perfecta, de la necesidad imperiosa de cuidar esta pequeña parcela, pero preciosa, de la producción literaria en español. En esta línea, se han podido leer recientemente titulares en la prensa española como el siguiente: «Las editoriales españolas descubren a los autores africanos que escriben en castellano» (Vera 2000: 33), es decir los de Marruecos y Guinea Ecuatorial, sobre todo. Y se ha podido también leer ideas, tan novedosas para el público español, que no para el occidental, del talante de "podemos contemplar el corazon de unos países complejos y desconcertantes que nos regalan una visión distinta de mundo". En este prometedor artículo se reseña a los guineanos María Msue Angüe, Francisco Zamora y Donato Ndongo.

Por lo tanto, nos parece una necesidad muy sentida la de una historia de la literatura guineana, que la consolide como tal, desde sus orígenes más remotos, y que sea general y plural en lo étnico, lo cultural y lo lingüistico, según postulan las nuevas teorías del canon literario, y la única que parece posible para las complejas realidades de las naciones africanas.

Y al habernos referido a lenguas, podemos fijarnos en el ejemplo de la República de la Nueva Sudáfrica, cuya reciente constitución de 1996 reconoce once lenguas oficiales: dos indoeuropeas, las dos oficiales hasta entonces, inglés y afrikaans (criollo holandes), y nueve lenguas africanas bantúes: zulu, xhosa, sotho del norte, sotho del sur, swana, tsonga, swati, venda y ndebele. Además se cita por su nombre, aunque ya no oficiales, pero sí con la obligación de ser defendidas y respetadas por el Estado, las lenguas bosquimanas y hotentotes de los primeros pobladores de Sudáfrica, lenguas de otras comunidades europeas minoritarias: portugués, alemán y griego; lenguas de la India: hindi, tamil, telegu y urdu; lenguas con fines de culto: árabe, hebreo, sánscrito; y el lenguaje de los signos.

El reto que supone dotar de carácter oficial, con todos los derechos que tal reconocimiento implica, a nueve lenguas africanas, la llamada Nueva Politica Lingüistica de 
Sudáfrica, es de una embergadura desconocida en el continente africano, lo que, en el caso de tener éxito acción tan novedosa, atrevida y agresiva, se constituiría en un claro ejemplo para otras muchas naciones del continente, y un motivo de regocijo grande para muchos lingüistas.

La República de Guinea Ecuatorial, por su parte, ha conocido tres Constituciones desde su independencia el dia 12 de octubre de 1968. La primera, la Constitución de 1968, establece, en su Artículo $7^{\circ}$, que el idioma oficial del Estado es el español y que el uso de las lenguas tradicionales será respetado (Maestre 1987a: 410) (García Domínguez 1977: 275). La Constitución de 1973, en un momento álgido de la tiranía del Presidente Macías Nguema, no cita en absoluto la cuestión de la lengua, supuestamente una imposición colonialista. Finalmente, unos años después del Golpe de Libertad del 3 de agosto de 1979, tenemos la vigente constitución, denominada Ley Fundamental de Guinea Ecuatorial (Carta de Akonibe), del 7 de septiembre de 1982, que es algo más explícita que la de 1968, por lo que respecta a cuestiones lingüísticas, las cuales de nuevo suscitan el interés del legislador. Sin embargo, el reconocimiento y defensa de las lenguas bantúes de la nación sigue siendo muy poco convincentes: «La lengua oficial de la República de Guinea Ecuatorial es el español. Se reconocen las lenguas aborigenes como integrantes de la cultura nacional) (Maestre 1987a: 438).

¿Pero, cuáles son estas lenguas aborigenes de Guinea Ecuatorial? Para acercarnos a ellas poseemos el trabajo de Antonio Quilis y Celia Casado-Fresnillo (1995), que nos ofrece el siguiente panorama (1995: 27-34): a) Bubi, de la isla de Bioko; b) Fang o pamue. La que cuenta con el mayor número de hablantes. Se extiende por todo el interior continental, ejerce una competencia fuerte con las lenguas de los pueblos playeros o asentados en la costa, y experimenta un gran avance en la isla de Bioko, donde es la primera lengua de Malabo; c) Cinco lenguas costeras del continente: benga, kombe o ndowé, baseke, balengue y bujeba. Con la excepción del ndowé, que aguanta un poco mejor, son lenguas poco estudiadas y en claro retroceso y disminución de hablantes; d) Annobonés, de la isla de Annobón. Mezcla de portugués y lenguas bantúes; e) Pichinglis o pichi (Pidgin English). Criollo inglés de Bioko (Malabo) y la costa continental (Bata). Uso muy localizado; y f) Español. Lengua oficial, de koiné, de trabajo entre las diferentes etnias. Lengua de la enseñanza y de la cultura.

Es decir, dos lenguas de cierta fuerza, el español y el fang, dos lenguas nativas con dificultades, el bubi y el ndowé, cuatro lenguas nativas muy deficitarias (benga, baseke, balengue, bujeba), y dos criollos de importancia relativa.

Pero toda lengua tiene derecho no sólo a su existencia sino a una literatura escrita, según defienden los lingüistas más prestigiosos. La experiencia de la Sudáfrica del pasado y del presente también puede servirnos de modelo para el estudio y promoción de la literatura ecuatoguineana. Investigadores sudáfricanos, como es el caso de Albert S. Gérard, han comenzado a defender recientemente que los estudios de literatura africana, ya sean de crítica o de historia literaria, han de ser comparativos, poliétnicos y translingüísticos (Gérard 1993: 1). Las historias de la literatura nacionales europeas del siglo XIX se construyeron sobre el principio de una nación-una lengua, pero esto no es posible ni en Sudáfrica ni en 
África en general, donde nos encontramos con unos panoramas nacionales muy complejos. África es así, y sus literaturas nacionales deben reflejar la realidad completa de sus variados corpora literarios (Gérard 1993: 44-45). Además, Sudáfrica desde el siglo XIX, representa, para toda África, el ejemplo más desarrollado de cultivo literario oral y escrito de sus lenguas nativas. Aparte, el cultivo literario de autores africanos en las lenguas de origen europeo -inglés y afrikaans- se encuentra entre los más avanzados, si no el que más, con toda probabilidad (Gérard 1993: 45-46). En conclusión, una gran variedad, pero también un factor decisivo de unidad y cohesión entre la creación de todos los grupos en juego: la simbiosis continua en la que todas las ramas llevan conviviendo desde hace muchos años, siglos incluso (Gérard 1993: 47).

Gérard publicó estas ideas poco antes de la caída de la antigua Sudáfrica. Pero con la nueva época el asunto de la construcción de una nueva historia de la literatura para la nueva nación "unida en su diversidad", según demandó el mismo presidente Mandela en su discurso inaugural de mayo de 1994, ha atraido un interés desconocido hasta entonces (Véase: Bialas 2000: 29-32). Lo que a nivel lingüístico se tradujo en el reconocimiento de once lenguas oficiales, a nivel literario produjo el descrédito de la situación anterior, propia del apartheid, en la que las diferentes literaturas en las varias lenguas de Sudáfrica se estudiaban, por razones políticas sobre todo, como pertenecientes a naciones diferentes, lo que se traducía en departamentos universitarios separados para inglés, afrikaans y lenguas africanas. Hoy en día, todos los sudafricanos son considerados ciudadanos de una sola nación sin distinción de razas y culturas, y una nación que se considere digna de tal nombre necesita narrarse a sí misma como tal, en lo historico en general, y en la historia de su literatura en particular. Todas las literaturas separadas anteriormente han debido pasar a ser concebidas, en los nuevos tiempos políticos, como miembros de un único sistema de carácter polifónico, intertextual, multilingüe y comparativo, y que, por supuesto, busque y analice los puntos en común y las interrelaciones ciertas.

Podemos citar dos hitos maduros dentro del capítulo de resultados de esta nueva orientación, en principio más adecuada para África, y que creemos debe ser aplicada sin demora al caso de Guinea Ecuatorial y su literatura nacional: El CSSALL de la Universidad de Durban-Westville (Durban), es decir, The Center for the Study of Southern African Literature and Languages, fundado en 1994; y la historia de la literatura del sur de África de Michael Chapman, cuyo título es Southern African Literatures, y que fue publicado en 1996.

El libro de Chapman se ocupa en muy buena medida de Sudáfrica, la nación más poderosa de subcontinente en cuestiones literarias, pero también de las otras naciones de dicho subcontinente que, según el autor, presentan un desarrollo histórico y cultural muy entrelazado. En concreto, se estudia la literatura de: Botswana, Lesotho, Swazilandia, Zimbabwe, Zambia, Malawi, Angola, Mozambique y Namibia. El prólogo del autor también nos indica (1996: $\mathrm{xv-xx}$ ) que se ocupará desde las expresiones de los primitivos bosquimanos hasta las últimas voces literarias de los estados independientes de hoy en día, cuyas fronteras son en general muy artificiales. Añade también que lo normal hasta entonces, sobre todo en Sudáfrica, era separar y describir de forma aislada las diferentes tradiciones literarias según lenguas, lo que ya conocemos, y que nunca se había llegado a un concepto único de la litera- 
tura sudafricana. La pregunta clave seria la siguiente: ¿las literaturas sudafricanas en lenguas xhosa o inglesa, por ejemplo, se habrian desarrollado de la misma manera sin el impacto de la una sobre la otra y sin olvidarse de los efectos producidos por todas las demás? Evidentemente no, y en esto ha de basarse la unidad. $Y$ en estos tiempos en los que la sufrida nación austral intenta superar los conflictos del pasado, la historiografia literaria puede ser de gran ayuda en su esfuerzo por construir una historia nacional integradora mediante un método comparativo que rastree las intersecciones. En una historia literaria sudafricana de este tipo caben la lenguas europeas -inglés, afrikaans y portugués para el sur de África-, las numerosas lenguas bantúes, grandes y pequeñas, y las huellas más o menos significativas de bosquimanos y hotentotes. Por ello, su trabajo se estructura en cuatro grandes apartados: I) Tradiciones orales; II) Literatura de europeos hasta comienzos del siglo XX; III) Literatura colonial; y IV) Escritores de las naciones independientes. Por consiguiente, la suma de tiempos primitivos, coloniales e independientes, africanos blancos y negros, lenguas indoeuropeas y bantúes: nadie puede considerarse ausente de la historia de Chapman, quien tampoco se olvida de reconocer la contribución decisiva de los traductores a la hora de dar a conocer las creaciones literarias de unas lenguas del sur de África en las otras. Lo mismo debe ser posible para la literatura de Guinea Ecuatorial.

A la espera de la prometida Nueva antología de la literatura guineana de Donato Ndongo-Bidyogo, que confiamos que ya no se demorará mucho, de momento seguiremos trabajando con la Antología de la literatura guineana, del mismo autor-antólogo, publicada en 1984, la cual incluye una completa introducción a la que debemos estar muy atentos (Ndongo 1984: 11-46). Para Ndongo, por literatura guineana debe entenderse una literatura escrita en castellano, el idioma común de los habitantes de Guinea Ecuatorial, de gran originalidad, dentro del ámbito de la literaturas hispánicas por la mezcla de africanidad, la cultura base, e hispanismo, la cultura adquirida. Aunque se trate de una literatura incipiente, dentro del contexto de la creación de una auténtica cultura nacional guineana, se debe hablar sin temor de una auténtica literatura guineana, por planteárnosla en una época en que ya no hace falta reivindicar el valor de la cultura africana, no inferior por haber sido ágrafa, y por estar sustentada por una raza, lengua, espacio geográfico vital, situación histórica y formas económicas comunes.

El estilo de esta literatura se caracteriza por una marcada propensión a la expresión simbólica, unida a una percepción animista del mundo, y por beneficiarse grandemente de la rica tradición oral guineana (fang, bubi, ndowe, etc.). No debe estar ausente de ella el reconocimiento a aquellos juglares que transmitieron de forma oral la leyendas o la épica del pueblo, que tanto han contribuido al nacimiento de la literatura escrita guineana, heredera de aquel papel mantenedor y transmisor del patrimonio histórico-literario común. Junto al respeto a la tradición, debe esforzarse por crear una literatura nueva, original, personal, producto de la contemporaneidad y de su siglo. Esta literatura participa del concepto de arte africano, concepto que como tal no suele aparecer lexicalizado en las lenguas del continente. El arte no puede ser sólo un ejercicio de autorrealización, sino que debe ser útil y estar concebido desde y para el pueblo. No debe busca sólo la belleza, ni lo contrario; debe ser atractivo y necesario al tiempo. El arte además es un fenómeno integral, una fusión de música, poesía, danza, máscaras (escultura) y pintura (motivos decorativos). Esta literatura no es 
anticolonialista, salvo excepciones, es decir, no presenta estridencias anticolonialistas, lo que le da un singularidad grande en el contexto africano. Sí se muestra, por el contrario, obsesionada por la dictadura de Macías. Muestra también un gran interés religioso, enfrentado al paganismo, por clara influencia de la formación intelectual del guineano a cargo de los misioneros. El español en que se escribe es un español muy interesante e influenciado por las lenguas nativas (guineanismos). Estas lenguas prestan una mayor atención a lo real, y un gusto extraordinario por el conocimiento de lo objetivo. Son muy observadoras de las pequeñas diferencias, son precisas, aprecian los cambios más sutiles, lo que se traduce en una gran riqueza de vocabulario y en una descripción minuciosa que se lleva al español. El sentido del idioma sería un don del africano, según Senghor y los otros fundadores de la Negritud. Este enriquecimiento es una de las mayores originalidades de la literatura nacional guineana. Pero además no debemos olvidarnos del "ritmo", de esa especial cadencia musical africana llevada a la palabra española, aportación ya realizada por los negros antillanos en la llamada literatura afrocubana. Finalmente, esta literatura no debe sentirse culpable por escribir en español. Se trata de una elección necesaria para abrirse y potenciar África en el mundo y para comunicarse entre africanos de distintas etnias, y, además, está demostrado que el abandono de las lenguas europeas suele ser sustituido por la nada, léase en el caso de Guinea la vuelta a la "autenticidad" de tiempos de Macías. Los teóricos de la Negritud lo vieron así de claro. Por otra parte, los negros africanos cuentan con la gran ventaja, frente al negro antillano ya citado, de conservar sus lenguas vernáculas, e incluso intentar escribirlas, y con ello la posibilidad de un pensamiento antónomo que sirva de amparo y refugio.

Con independencia de lo que la nueva antología de Ndongo pueda aportarnos, la que tenemos tiene un gran mérito, pero es insuficiente para nosotros, ya que se basa en un concepto muy restringido de literatura africana o guineana: la escrita en lengua española por guineamos de las diversas etnias africanas. Al tratarse de una literatura en formación, no creemos que pueda prescindir de nadie ni de nada. Proponemos, en consecuencia abrir radicalmente este canon, siguiendo los pasos emprendidos por la últimas descripciones de la literatura sudafricana (Chapman). Y proponemos abrirlo en dos grandes líneas, es decir, sobre todo hacia la literatura autóctona, culta o popular, en lenguas nativas africanas, y además dejar participar a la literatura de la tribu blanca, colonial o exiliada, que históricamente, racialmente, y, sobre todo, sentimentalmente ha estado unida, y sigue estándolo, a Guinea Ecuatorial. Donato Ndongo menciona a los numerosos autores españoles, emigrados a Guinea, que escribieron sobre temas guineanos o ambientaron sus relatos en esos territorios, pero para concluir que no tienen cabida en su concepto de literatura guineana. Sí reconoce que resulta obligado tomarlos como punto de referencia, como influencias decisivas en las primeras generaciones de escritores guineanos (Ndongo 1984: 16). Aparte de descubrirnos una sospechosa línea de continuidad que debilita los criterios empleados, creemos que esta palabras denotan con claridad lo excesivamente restringido que resulta el concepto de literatura guineana en juego. Esto no nos impide admitir nuestra admiración por el trabajo pionero de Ndongo.

Pero repetimos que nuestra historia de la literatura guineana no puede basarse sólo en los criterios y en los autores incluidos en esta antologia. La historia que proponemos debe- 
ría ocuparse de los siguientes apartados, no muy alejados de los considerados por Chapman para confeccionar su libro:

I.- Literatura pre-bantú en Guinea Ecuatorial. Probablemente, no sería dificil encontrar huellas de los primeros habitantes africanos en la mitología o la literatura oral de los pueblos bantúes de guinea Ecuatorial.

II.- En su antología de la literatura guineana de 1984, Donato Ndongo recuerda la figura histórica de Juan Latino, un negro probablemente guineano traído a España a la edad de doce años, en 1528, para servir como esclavo en el palacio de El Gran Capitán, y que llegó a figurar entre los máximos eruditos del Siglo de Oro. El antólogo rechaza reivindicar su figura y convertirlo en una especie de patriarca de las letras guineanas, ya que, a pesar de su sangre africana, Guinea Ecuatorial no existía en el siglo XVI, por lo que sus obras no pueden estudiarse como engarzadas dentro del imprescindible espacio vital o histórico del pais (Ndongo 1984: 1516). La peripecia vital de Juan Latino, sin embargo, nos trae a la memoria la de un maestro de las letras contemporáneo suyo, procedente también de otro continente, el americano en este caso, e implantado en la península ibérica. Nos estamos refiriendo a Gómez Suárez de Figueroa, famoso por el sobrenombre de el Inca Garcilaso de la Vega, al ser hijo ilegítimo del capitán Garcilaso de la Vega y de la princesa india Isabel Chimpu Ocllo. El Inca Garcilaso nació en Cuzco en 1539, y fue llevado a España en 1560, donde también llegó a ser una figura destacada del Siglo de Oro. Después de su fallecimiento, acontecido en 1616, se le concedió el honor de ser enterrado en una capilla de la catedral de Córdoba (Avalle-Arce 1970). A los historiadores de la literatura peruana, y a los promotores de la literatura latinoamerica en su conjunto, de nuestros tiempos, no se les olvida incluir la figura de el Inca Garcilaso, tal vez no como historia sino más bien como prehistoria de la misma. Defenderíamos un mismo lugar de privilegio para Juan Latino respecto a la literatura guineana.

III.- Mariano de Castro y $\mathrm{M}^{\mathrm{a}}$ Luisa de la Calle aseguran que el número de obras dejado por exploradores, funcionarios, misioneros y viajeros que por una u otra razón llegaron a Guinea Ecuatorial, que se decidieron a plasmar sus impresiones por escrito, no es escaso, y nos citan, asimismo, los nombres de Marcelino de Andrés, Moros Morellón, P. Usera, P. Martínez Sanz, J.J. Navarro y Guillemard de Aragón (1992: 7). Pero sí hay un nombre decisivo entre los primeros exploradores españoles que escudriñaron los rincones entonces desconocidos de la actual Guinea Ecuatorial es el del vitoriano Manuel Iradier (1854-1911), quien el 16 de mayo de 1875 llega, en su primer viaje de exploración que durará 834 días, a Fernando Poo, y quien más tarde, junto a Ossorio y Montes de Oca, explora para España el país del Muni entre 1884 y 1886 (De Castro 1998: 235-240), lugares todos ellos donde izará el pabellón de España por primera vez en numerosas ocasiones, con independencia de constituir una hazaña quimérica de un soñador y un filántropo, así como un hito de las exploraciones geográficas del continente misterioso (Martínez Salazar 1993: 9-10). Pero Iradier, aparte de explorador, fue un autor prolijo de buen número de libros y artículos sobre sus viajes, como es el caso de: Africa. Fragmentos de un diario de viajes de exploración en la zona de Corisco, 
de 1878, o de su obra magna: Africa. Viajes y trabajos de la Asociación Euskara La Exploradora (1987) (Martínez Salazar 1993: 162-163). Iradier, por lo tanto, no puede estar ausente de una historia general de la literatura de Guinea Ecuatorial de las características que estamos definiendo.

IV.- Para conocer y abordar el estudio de la literatura colonial hispanoguineana, de los momentos del asentamiento más consolidado, contamos con la inestimable ayuda de una publicación muy reciente: la antología Estampas y cuentos de la Guinea Española, a cargo de Jacint Creus y Gustau Nerín (1999). Los editores, en una interesante introducción (Creus 1999: 11-17), reconocen que la única colonia española en el África negra jamás llegó a inspirar una cantidad de obras literarias equiparable al de las posesiones de Francia o Gran Bretaña, cosa lógica por otra parte, y que de los grandes escritores hispanos, sólo León Felipe piso territorio guineano y le dedicó algunos versos. Pero ello no impide afirmar que sí que se generó un volumen notable de literatura, escrita no por profesionales de la misma, sino por los protagonistas de la empresa colonizadora: misioneros, funcionarios, viajeros, y algunos pocos guineanos. Tal vez por ello esta literatura no se caracteriza por lo fantástico o maravilloso, por ejemplo, sino por una vinculación estrechísima con la realidad y por el deseo de reflejar lo más fielmente posible la vida colonial en aquel territorio, hasta el punto de que la narración llega a alcanzar tintes periodísticos. La ficción se vio, por lo tanto, relegada a una importancia menor: el argumento de las pocas novelas existentes suele presentar una función secundaria o de mero hilo conductor a través del cual se describen determinadas realidades del país. En consecuencia, los géneros favoritos serán: libros de viajes, epistolarios, descripciones geográficas, compilaciones etnográfias, etc. Por otra parte, los antólogos no olvidan incluir un lamento por la ausencia de los autores africanos, pero se disculpan afirmando que la literatura escrita guineana no empezó a florecer hasta después de la independencia

V.- Por otra parte, tampoco es cierto del todo que no existiera una literatura colonial nativa culta o escrita en aquellos años. Si se busca se encuentra. Por ejemplo, Donato Ndongo, en su antologia, nos cuenta como José Mas, autor de relatos costumbristas a principios de siglo ambientados en Fernando Poo, confesó que cuando conoció que el Premio Goncourt de 1921 fue concedido a la novela Batuala, escrita por un negro del Congo, le pareció inconcebible que éste tuviera aptitudes de escritor (Ndongo 1984: 12). Pero para ser justos, a pesar de la sorpresa de colonialista prejuiciado, que hay que localizar sin duda en su época y en lo inusual entonces del hecho del éxito de autores africanos en la lengua de sus colonizadores, hay que recordar que supo superarse y tradujo casi de inmediato esta obra, como el mismo Ndongo recoge también en nota: «René Maran: Batuala. Prólogo, traducción y notas de José Mas. Madrid: V.H. Sanz Calleja Ed., 1922». También nos señala Ndondo la existencia de todo un hito en lengua española, la novela del africano Leoncio Evita Cuando los combes luchaban, publicada en Madrid en 1953 por el Instituto de Estudios Africanos, prologada por Carlos González Echegaray. Parece ser que Echegaray, el que fuera un gran africanista, reconoció 
que cuando el joven Leoncio le pidió que le prologara el libro, no pensaba que un guineano pudiera escribir una obrita tan aceptable (Ndongo 1984: 12). Sus prejuicios no estuvieron bien, pero también supo reaccionar y cambiar de opinión, como lo demuestra que escribiera el prólogo y que, probablemente, facilitara la publicación de este trabajo que podemos considerar esencial para la historia de una literatura guineana. En consecuencia, se trata de una línea que necesita mucha mayor investigación y búsqueda paciente. Tiene que haber más ejemplos de literatura colonial guineana escrita por guineanos de raza negra, que incluso, lo que la convertiría en interesantísima, opinara sobre los españoles y la cultura española, e intentara describirla desde la perspectiva nativa.

Por contraste, en el polisistema literario sudáfricano no existen dudas acerca de la importancia de la literatura en lenguas africanas durante los tiempos coloniales. Por lo que respecta al zulú, los primeros que estudiaron dicha lengua y su rica literatura oral y poesía laudatoria a los grandes jefes guerreros, fueron los misioneros europeos, pero la literatura escrita comenzó muy pronto, en concreto en los años 20 del siglo XX, con una gran influencia de géneros europeos: drama, prosa, poesía, y con un plantel de autores de talento.

VI.- Por lo que se refiere a la literatura oral de Guinea Ecuatorial, contamos con los cuatro volúmenes recopilatorios de cuentos de las principales etnias del pais, publicados por el Centro Cultural Hispano-Guineano en 1991 y 1992: Cuentos de los Ndowe de Guinea Ecuatorial, Cuentos de los Fang de Guinea Ecuatorial, Cuentos Annoboneses de Guinea Ecuatorial, Cuentos Bubis de Guinea Ecuatorial. El autor principal de todos es Jacint Creus, que cuenta con la colaboración de $\mathrm{M}^{\mathrm{a}}$ Antonia Brunat en los tres últimos, y de Pilar Carulla en el último.

La literatura de tradición oral sigue viva en muchas sociedades africanas (Preminger 1993: 77), y éste hecho nos permite un abanico de posibilidades para el estudio folclórico y literario muy estimulante. Pero esto no quiere decir que no debamos darnos prisa, pues se trata de una literatura, casi por definición, en declive en nuestros tiempos. Cuddon afirma que precisamente el hecho de que se ponga por escrito suele ser el signo más claro que revela dicho declive (1998: 322). Y éste es el momento en que se encuentra la literatura popular de Guinea Ecuatorial.

Por otra parte, si se consultan las introducciones de los cuatro volúmenes (Creus 1991a: 9-23) (Creus 1991b: 9-19) (Creus 1992a: 9-15) (Creus 1992b: 9-17), comprobaremos que se ha tratado de un trabajo clásico de recogida de literatura popular, con un gran número de informantes, cuyos nombres se incluyen en señal de agradecimiento, a los que se acerca uno con una grabadora, y que suelen mostrarse muy amables y pacientes.

De esta forma, podemos disfrutar, por lo que se refiere a los ndowe, del ciclo de Ndjambu y su familia, asi como de numerosos cuentos o fábulas protagonizadas por animales, en un proceso que gira desde lo familiar a lo social y sus conflictos. Entre estos últimos sobresalen los protagonizados por la tortuga: longeva, 
sobria, reflexiva, sabia y astuta. Entre los cuentos de los fang, destaca cl ciclo de Beme y su familia, con sus humorísticos enfrentamientos hombre-mujer, así como los cuentos de animales. En estos cuentos tiene una importancia mayor el tema de la brujería, lo que permite la introducción de seres y objetos maravillosos. El caso de la literatura de la pequeña y aislada isla de Annobón es muy diferente. Se trata de un mundo reducido y desconocido, cuyos cuentos no son clasificables en ciclos, y que parece relacionado con los antiguos ritos de iniciación a la madurez de las primitivas sociedades de cazadores (Creus 1992a 11). Es decir, es estudio de los cuentos tradicionales de transmión oral de los pueblos bantúes guineanos puede llevarnos muy atrás en la historia hacia los tiempos ancestrales. En último lugar, los bubis presentan una diversidad tal que también es imposible de clasificar en ciclos. Además, los bubis de la antigua Fernando Poo han sido los guineanos que experimentaron una colonización más larga e intensa, y eso se aprecia en los temas de los cuentos: no faltan referencias a los avances técnicos del hombre blanco, extraterrestres y platillos voladores, leyendas como la de San Jorge y el dragón, la casita de chocolate o el muchacho y la rana. Y, muy especialmente, que se refieren a viajes del hombre negro a Europa, donde se hace rico en el país de los blancos. En una sección anterior, enfatizábamos la necesidad de buscar literatura guineana donde se expresara la visión del africano respecto al europeo y su cultura, y aquí tenemos un ejemplo de aquello a lo que nos referíamos.

Pero los cuatro volúmenes de Creus y sus colaboradoras encierran aún otro elemento esencial. Los cuentos, en español, son traducciones, probablemente realizadas de forma espontánea por los propios informantes guineanos. Y esto no debe bastarnos, como tampoco les basta a los recopiladores: la cuentos populares y tradicionales guineanos no pueden ni deben renunciar a ser pasados a papel en su lengua original, con independencia de las indudables y positivas ventajas que su traducción a la lengua española pueda aportar. Tal vez por ello, los cuatro volúmenes incluyen un apéndice final con veinticinco cuentos cada uno en cada una de las cuatro lenguas originales: ndowe (Creus 1991a: 227-277), fang (Creus 1991b: 213-256), annobonés (Creus 1992a: 160-190) y bubi (Creus 1992b: 163-190). Por supuesto, para estos apéndices se ha necesitado la ayuda de varios colaboradores nativos. Las dificultades lingüisticas de estas transcripciones son muy importantes, ya que mientras el fang posee una cierta fijación, tradición de escritura y bibliografia, esto no ocurre con el ndowe o el annabonés, por ejemplo. Todavia es muy necesario efectuar una descripción y normalización decididas de las lenguas aborígenes de Guinea Ecuatorial, y un buen apoyo en este camino puede suponerlo la publicación de volúmenes bilingües, según el método apuntado por estos cuatro que nos ocupan, y en dos direcciones: traducciones de literatura guineana al español o a otras lenguas internacionales, y traducciones de clásicos españoles, africanos o universales a las lenguas de Guinea Ecuatorial. 
VII.-En Sudáfrica, la producción literaria en lenguas nativas sigue siendo muy abundante, pero se observa que de manera creciente los autores africanos de raza negra abandonan sus lenguas bantúes maternas por el inglés. Este paso, de lengua africana a lengua europea, sin embargo, no se ha producido sin grandes conflictos para los nuevos escritores africanos bilingües por esta cuestión. La sensación de traición a la propia lengua y cultura es muy grande.

Esta tendencia no debe ser estorbada, pero no debe llevar tampoco a abandonar el cultivo literario escrito de las lenguas nativas africanas. En Sudáfrica, el inglés nunca desterrará a las poderosas lenguas africanas locales hoy oficiales, pero en el caso de Guinea Ecuatorial hay que poner más cuidado.

Abrirse al mundo es importante, pero no lo es todo. La solución transitoria podría estar en volúmenes bilingües bubi-español o fang-español, por ejemplo, mucho más fáciles de rentabilizar. La traducción, como en otros tantos casos de la historia, podría ser de gran ayuda para consolidar una literatura guineana en lenguas africanas. ¿Ha sido la Biblia traducida en su totalidad al fang, al bubi o al annobonés? Y ¿El Quijote? ¿Y Chinua Achebe y su literatura nigeriana en lengua inglesa?

Por otra parte, la literatura guineana reciente en español cuenta, por ejemplo, con las espléndidas novelas de Donato Ndongo-Bidyogo (1950- ): una trilogía, denominada genéricamente Los hijos de la tribu, de la que, por el momento, sólo se han publicado las dos primeras entregas. La primera, Las tinieblas de tu memoria negra, de 1987 (Ndongo 2000), presenta un título inspirado, con toda intención, en unos versos del senegalés L.S. Senghor, el fundador del movimiento de la Negritud, que se reproducen además en una cita inicial. La segunda, Los poderes de la tempestad, es de 1997. Entre las tres se pretende, para cuando el proyecto esté terminado, presentar la historia de una generación de guineanos a través del colonialismo, la independencia, la dictadura y el presente de Guinea Ecuatorial.

VIII.- Por una parte, la tribu blanca en el exilio no se ha olvidado nunca del todo de Guinea Ecuatorial como tema literario, como, por otra, no han dejado de aparecer, de tanto en tanto, españoles que han descubierto en este país su tema de inspiración.

Entre los primeros podemos citar a V. López Izquierdo, autor de Manto verde bajo el sol, de 1973, Carlos Fleitas Alonso, con su Guinea. Episodios de la vida colonial. Relatos, de 1989, y a Fernando Garcia Jimeno, con El paraiso verde perdido, Guinea, de 1999. Entre los segundos, a Manuel Leguineche, con La tribu. Guinea Ecuatorial, 1979-1996. Novela, de 1980 (Leguineche 1996), y a José Manuel Novoa, autor de A través de la magia bubi. Por las selvas de Guinea, de 1991.

Hemos analizado hace algunas secciones, para proponer su inclusión, la literatura de aquellos exploradores europeos que según palabras de Javier Reverte (1997: 21) convirtieron durante muchos siglos a África en un mito duradero, en una leyenda imperecedera, en un sueño tangible, cuyo halo de ensoñación sigue sin 
apagarse, como demuestra esta afición por el recuerdo y la añoranza literaria de la tribu blanca de Guinea Ecuatorial desde su exilio y progresiva desaparición. La literatura del recuerdo sería uno de sus últimos asideros a los que agarrarse y no perder su personalidad.

\section{CONCLUSIONES}

1. La literatura guineana es parte de la gran literatura en español, sin fronteras, sin embargo ésta se ocupa muy poco de ella. Es necesario introducirla definitivamente en el legado general de la historia completa de las literaturas hispánicas.

2. Afianzar esta literatura no es enfrentarla a la española, cosa imposible si se escribe sobre todo en español, sino en compartir con ella lo que haya que compartir, y diferenciar lo peculiar y que enriquezca el conjunto: el fruto mejor de una historia de la literatura especializada como es el caso de la que estamos proponiendo.

3. Defendemos las grandes ventajas de un criterio amplio que presida una historia general, que tenga un carácter diacrónico que se ocupe del paso de los siglos, ya que el presente de una literatura guineana en español no se puede entender sin el pasado, y también sincrónico: estudiar cada fase y juzgarla desde su tiempo, y aceptarlas todas ellas en lo bueno y en lo malo.

4. Una visión positiva, en la que nadie que haya querido y escrito sobre Guinea Ecuatorial y que lo haya hecho con interés literario o, al menos, documental o histórico, deba quedar excluido.

5. Proponemos un concepto muy al día: multicultural, multilingüístico, y creador de puentes de comunicación entre lenguas y culturas imposibles de separar aunque muy distintas. El desarrollo de cada una de éstas se muestra dramáticamente influenciado por los contactos con las que comparte destino y nacionalidad.

6. En esta nueva visión global de la literatura guineana, la traducción es fundamental para afianzar algunas ramas.

\section{BIBLIOGRAFÍA}

AVALLE-ARCE, Juan Bautista (1970) (ed). El Inca Garcilaso en sus "Comentarios». Antologia vivida. Madrid: Gredos

BIALAS, Zbigniew (2000). «Redefining Literary Histories: The Case of South Africa», in The European English Messenger. IX/1, pp. 29-32.

BLOOM, Harold (1996) (1 $1^{\mathrm{a}}$ 1994). The Western Canon. The Books and School of the Ages. London: Papermac.

CHAPMAN, Michael (1996). Southern African Literatures. London and New York: Longman.

COLVIN, Roy (1998). South Africa. The Essence. South Africa: Published by the author. 
Constitution of the Republic of South Africa, the. As adopted on 8 May 1996 and amended on 11 October 1996 ny the Constitutional Assembly.

CREUS, Jacint (1991a): Cuentos de los Ndowe de Guinea Ecuatorial, Ensayos, 6. Malabo: Centro Cultural Hispano-Guineano.

CREUS, Jacint y $\mathrm{M}^{\mathrm{a}}$ Antonia Brunat (1991b): Cuentos de los Fang de Guinea Ecuatorial. Ensayos, 7. Malabo: Centro Cultural Hispano-Guineano.

CREUS, Jacint y $\mathrm{M}^{2}$ Antonia Brunat (1992a): Cuentos Annoboneses de Guinea Ecuatorial. Ensayos, 8. Malabo: Centro Cultural Hispano-Guineano.

CREUS, Jacint, Ma Antonia Brunat y Pilar Carulla (1992b): Cuentos Bubis de Guinea Ecuatorial. Ensayos, 9. Malabo: Centro Cultural Hispano-Guineano.

CREUS, Jacint (1997): Identidad y conflicto: aproximación a la tradición oral en Guinea Ecuatorial. Madrid: Los libros de la Catarala.

CREUS, Jacint y Gustau Nerin (eds) (1999): Estampas y cuentos de la Guinea Española. Prólogo de José María Parreño. Madrid: Cuentos de Clan.

CUDDON, J.A. (1998). Dictionary of Literary Terms and Literary Theory. Revised by C.E. Preston. London: Penguin.

DE CASTRO, Mariano y Ma Luisa de la Calle (1992). Origen de la colonización española de Guinea Ecuatorial. Valladolid: Secretariado de Publicaciones-Universidad de Valladolid.

DE CASTRO, Mariano y Donato Ndongo (1998): España en Guinea. Construcción de un desencuentro: 1778-1968. Epílogo de José Urbano Martínez Carreras. Madrid: Ediciones Sequitur.

DE LA FUENTE, Ricardo (ed) (1999). La historia de la literatura y de la crítica. Salamanca: Ediciones Colegio de España.

FLEITAS ALONSO, Carlos (1989): Guinea: episodios de la vida colonial: relatos. Madrid: Agencia Española de Cooperación Internacional-Instituto de Cooperación para el Desarrollo.

GARCÍA GIMENO, Fernando (1999). El paraiso verde perdido, Guinea. Madrid: Pues.

GÉRARD, Albert S. et al. (1993). Comparative Literature and African Literatures. Pretoria: Via Afrika.

IRADIER, Manuel (1878). Africa. Fragmentos de un diario de viajes de exploración en la zona de Corisco. Madrid: Imprenta de Fortanet.

IRADIER, Manuel (1887). Africa. Viajes y trabajos de la Asociación Euskara La Exploradora. 2 Vols. Vitoria: Imprenta de la viuda e hijos de Iturbe.

LEGUINECHE, Manuel (1996): La tribu: Guinea Ecuatorial, 1979-1996. Madrid: EspasaCalpe.

LÓPEZ IZQUIERDO, V. (1973). Manto verde bajo el sol. Valencia: Imprenta-Editorial J. Doménech. 
MAESTRE ALONSO, Juan (1987a): Constituciones y leyes politicas de América Latina, Filipinas y Guinea Ecuatorial. Tomo I, México, Nicaragua, Penú y Guinea Ecuatorial. Sevilla: Escuela de Estudios Hispano-Americanos.

MAESTRE ALONSO, Juan (1987b): Constituciones y leyes politicas de América Latina, Filipinas $y$ Guinea Ecuatorial. Vol. II. Sevilla: Escuela de Estudios HispanoAmericanos.

MARTÍNEZ SALAZAR, Ángel (1993). Manuel Iradier Las azarosas empresas de un explorador de quimeras. Prólogo de Lily Litvak. Barcelona: Ediciones del Serbal.

NDONGO-BIDYOGO, Donato (1984): Antologia de la literatura guineana. Madrid: Editora Nacional.

NDONGO-BIDYOGO, Donato (1997): Los poderes de la tempestad. Madrid: E. MorandiCooperación Española/Ediciones del Centro Cultural Hispano-Guineano de Malabo.

NDONGO-BIDYOGO, Donato (1999). «Relaciones entre España y Guinea Ecuatorial: Anatomía de un desencuentro permanente», cn Estudios Africanos. Vol XIII, $\mathrm{n}^{0} 24$. Madrid: Asociación Española de Africanistas, pp. 51-63.

NDONGO-BIDYOGO, Donato (2000) (1 ${ }^{\mathrm{a}}$ 1987): Las tinieblas de tu memoria negra. Barcelona: Ediciones del Bronce.

NERIN, Gustau (1998): Guinea Ecuatorial, historia en blanco y negro. Hombres blancos y mujeres negras en Guinea Ecuatorial (1843-1968). Barcelona: Península.

NOVOA, José Manuel (1991): A través de la magia bubi: por las selvas de Guinea. Zaragoza: Edelvives.

NWOGA, Donatus Ibe (1990). «Bilingualism and Literary Creativity: An African Perspective on Literature in English», in Literature(s) in English-New Perspectives. Edited by Wolfgang Zach. Frankfurt am Main: Verlag Peter Lang, pp. 95-108.

POZUELO YVANCOS, José Maria y Rosa Maria Aradra Sánchez (2000). Teoria del canon y literatura española. Madrid: Cátedra.

QUILIS, Antonio y Celia Casado-Fresnillo (1995). La lengua española en Guinea Ecuatorial. Madrid: UNED.

REVERTE, Javier (1997). El sueño de Africa. En busca de los mitos blancos del continente negro. Madrid: Anaya-Mario Muchnik.

RIESGO, Juan Manuel (1999). «Sudáfrica ayer, hoy y mañana», en Estudios Africanos. Vol. XIII, $n^{n}$ 24. Madrid: Asociación Española de Africanistas, pp. 99-124.

South Africa's New Language Policy. The Facts. Pretoria: Department of National Education. VERA, Juana (2000). «Las editoriales españolas descubren a los autores africanos que escriben es español», en El Pais. Domingo 16 de abril, p. 33. 